\title{
Commentary: Valuable insights from morbidity coding in primary care
}

Tom Fahey

McAlister and colleagues present a challenging paper, which shows the value of high quality, routinely collected data in primary care. ${ }^{1}$ Their research gives a representative picture of current clinical practice for patients with heart failure, highlighting the variations in diagnosis and follow up in relation to socioeconomic status. Their findings are consistent with evidence that shows socioeconomic status is an independent marker of admission to hospital in patients with heart failure. ${ }^{2}$ They found that lower socioeconomic status was also an independent risk marker for development of heart failure and that patients from lower socioeconomic groups were less likely to consult their general practitioner for continued management than those in higher socioeconomic groups.

Inevitably several questions are raised when trying to interpret the results of observational studies of this sort and set them in the context of everyday clinical practice in primary care. The diagnosis of heart failure on clinical grounds (history and physical examination) is difficult to establish. ${ }^{3}$ For example, the only consistent clinical finding that is helpful for establishing the diagnosis of left ventricular systolic dysfunction (the commonest cause of heart failure) is an abnormal apical impulse (in particular sustained duration). ${ }^{3}$ Other helpful diagnostic tests such as chest radiography (cardiomegaly) or electrocardiography (left bundle branch block) may not be utilised by general practitioners, either because of lack of availability or because of concerns about accurate interpretation. Echocardiography is the ideal means of establishing the diagnosis of heart failure. A prevalence study in the West Midlands, which comprised a random sample of 3960 patients aged over 45 in primary care, showed that half of those who were found to have heart failure had no symptoms. ${ }^{4}$ The authors acknowledge that there was no independent verification of heart failure and reasonably suggest that clinicians are unlikely to apply different definitions or diagnostic thresholds, depending on socioeconomic status. Whether there is any confounding because of differential availability of echocardiography and consequent Read code diagnostic labelling is harder to judge.
Another issue that arises relates to health seeking behaviour. It could be hypothesised that initial presentation and attendance for continuing care with relation to socioeconomic status might be confounded by differential health seeking behaviour in different socioeconomic groups. The fact that no socioeconomic differences have been shown in patients presenting to their general practitioners with chest pain in primary care, makes this an unlikely finding. ${ }^{5}$ Lastly, there might be a possibility of misclassification and subsequent confounding because of the way in which general practitioners code individual consultations. Patients of lower socioeconomic status are more likely to have greater comorbidities and may have more problems that require dealing with in a consultation. Because of time constraints, general practitioners tend to enter only one Read code at each consultation, therefore under-representing comorbidities such as heart failure in sicker patients. ${ }^{6}$

McAlister and colleagues show that studies of morbidity in primary care provide a different form of information concerning patient care compared with other routine datasets. Their finding that patients of lower socioeconomic status seem to have less ongoing contact with their general practitioner requires further evaluation and attention.

\section{Competing interests: None declared.}

1 McAlister FA, Murphy NF, Simpson CR, Stewart S, MacIntyre K, Kirkpatrick M, et al. Influence of socioeconomic deprivation on the primary care burden and tiseathent of patients with a diagnosis or heart 2 Struthers AD, Anderson G, Donnan PT, MacDonald T. Social deprivation increases cardiac hospitalisations in chronic heart failure independent of disease severity and diuretic non-adherence. Heart 2000;83:12-6.

3 Badgett RG, Lucey CR, Mulrow CD. Can the clinical examination diagnose left-sided heart failure in adults? JAMA 1997;277:1712-9.

4 Davies MK, Hobbs FDR, Davis RC, Kenkre JE, Roalfe AK, Hare R, et al. Prevalence of left-ventricular systolic dysfunction and heart failure in the echocardiographic heart of England screening study: a population based study. Lancet 2001;358:439-44.

5 Richards H, McConnachie A, Morrison C, Murray K, Watt G. Social and gender variation in the prevalence, presentation and general practitioner provisional diagnosis of chest pain. J Epidemiol Community Health provisional dia

6 Porcheret M, Hughes R, Evans D, Jordan K, Whitehurst T, Ogden H, et al. Data quality of general practice electronic health records: the impact of a programme of assessments, feedback and training. J Am Med Infor Assoc 2004;11:78-86.

(Accepted 5 March 2004)

doi $10.1136 /$ bmj. 38084.560475 .55
Tayside Centre for General Practice, University of Dundee DD2 4AD Tom Fahey professor of primary care medicine t.p.fahey@ dundee.ac.uk

\section{One hundred years ago}

\section{Reduction of dislocations immediately after the accident}

It does not seem to be generally known with what extreme ease a dislocation may be reduced if tackled immediately after the accident, if the opportunity occurs.

Sixteen years ago I dislocated my shoulder in a fall from a tricycle and I got a gentleman to put it in for me the moment I rose from the ground. Three weeks ago I had a similar accident, from a side slip when on a bicycle, to the same arm. Once again on asking a bystander to hold me firmly by the wrist while I gave a good pull, the head of the humerus was instantly replaced.

On each occasion the reduction was quite painless and could have been effected by a fairly strong child of 10 or 12 . On each occasion I had very little subsequent pain after a bandage had been applied, and I recovered the full range of movements of my arm in three weeks.

Walter G. Walford, M.D., London, N.W. (BMJ 1904;i:661) 